American Journal of Pharmacology and Toxicology 6 (4): 107-108, 2011

ISSN 1557-4962

C 2011 Science Publications

\title{
Microtia After Ovulation Induction with Letrozole
}

\author{
Mohammed Al-Sunaidi, M.D. \\ Department of Obstetrics and Gynecology, College of Medicine, \\ King Khalid University, ABHA, P.O. Box 641, Saudi Arabia
}

\begin{abstract}
Problem statement: Letrozole gained lots of interest over the past decayed as a medication for ovulation induction to achieve monofollicular results, although few retrospective analysis of congenital anolamalies detected for babies who were conceived via this medication; the dispute still exist and the need for large multicenter studies are needed to resolve this issue. Approach: In the current report; we report a case of microtia who was conceived as a result of ovulation induction with letrozole. Results: This case draws our attention to the safety of letrozole as an ovulation induction medication. Conclusion: The reported case here mandates that babies delivered as a consequence of ovulation induction with aromatase inhibitors should be examined antenatal and postnatally for possible congenital anomalies and to be reported to settle the argument weather theses medications are safe or not in term of ovulation induction.
\end{abstract}

Key words: Letrozole, congenital anomalies, ovulation induction, infertility

\section{INTRODUCTION}

Letrozole is a third-generation aromatase inhibitor which has been used as a drug for ovulation induction over the past decay. The recommended dose for ovulation induction is $5 \mathrm{mg}$ of letrozole daily which is associated with a higher number of follicles and a higher pregnancy rate (Al-Fadhli et al., 2006). The safety of the drug as an ovulation induction medication questioned by some authors as they presented that the incidence of locomotor malformations and cardiac anomalies were higher in letrozole group (Biljan et al., 2005). This was challenged by another group who showed that the drug is safe in induction of ovulation and the congenital malformation were similar in those who conceived using other ovulation induction medications and those who conceived after receiving letrozole (Tulandi et al., 2006).

Here we present a case of microtia in a four years old girl who was conceived after using letrozole as ovulation induction medication.

Case report: We report here a case of a young girl who was conceived after ovulation induction with letrozole, after delivery she was found to have absence of the left auricle.

The mother presented with secondary infertility and she was diagnosed to have polycystic ovary syndrome causing an ovulation.

She was started on letrozole $5 \mathrm{mg}$ as a method of ovulation induction from the second day of the menstrual cycle for five days.

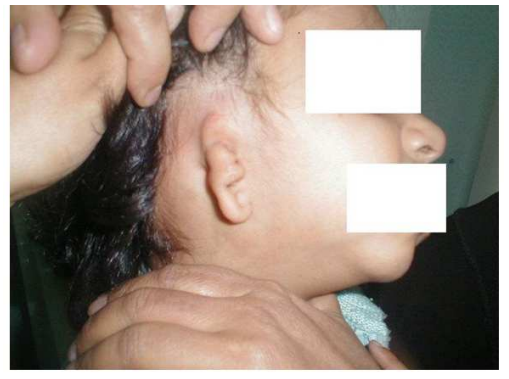

Fig. 1: The picture of the baby showing microtia of the right ear

Her pregnancy was singleton. During the first trimester she was on folic acid $5 \mathrm{mg}$ daily and the antenatal investigations were within normal. She was not exposed to radiation or medications. Thereafter her antenatal care period went uneventful and she gave birth to a baby girl weighing $2.7 \mathrm{~kg}$. The newborn was found to have absence of the right external ear Fig. 1. The family denied any history of same deformity.

The baby did not have other congenital deformities.

Aromatase is a cytochrome P450 enzyme responsible for the last step in estrogen biosynthesis, catalyzing the aromatization of androstenedione and testosterone into estrone and estradiol. Aromatase (CYP19) is present in several tissue and organ systems, including ovary, fat, muscle, liver and breast (Haynes et al., 2003). Letrozole is a potent non-steroidal aromatase inhibitor that produces approximately $99 \%$ inhibition of estrogen biosynthesis at the dose of $2.5 \mathrm{mg} \mathrm{day}^{-1}$ 
(Haynes et al., 2003). Increased interest is currently being paid to the possible clinical application of aromatase inhibitors as ovulation inducing agents (Casper and Mitwally, 2006; Holzer et al., 2006). Potential advantages offered by the use of aromatase inhibitors over clomiphene citrate in ovulation induction include a lack of peripheral anti-estrogenic effects, particularly on the endometrium and the cervical mucus and an ability to limit the ovarian response to monoovulation (Casper and Mitwally, 2006).

Treatment of endometriosis and uterine fibroids represent additional areas of application for aromatase inhibitors in premenopausal women (Ziegler et al., 2005).

When a drug is used to treat conditions that affect women of reproductive age, any potential developmental hazard posed by the agent is a matter of particular concern. No information is currently available regarding the outcome of human pregnancies exposed to letrozole at any stage.

Data from the manufacturer (Femara ${ }^{\circledR}$ patient prescribing information) indicate that letrozole exerts potent embryotoxic effects in rats and rabbits, at doses lower than the daily recommended human dose.

It is well known that, for the majority of teratogenic agents, organogenesis represents the most sensitive phase during which malformations are induced (Shepard and Lemire, 2004). But this does not eliminate totally the risk of embryotoxicity (Biljan et al., 2005; Tiboni et al., 2008; Dickey, 2009).

Tulandi et al. (2006) reported no increased teratogenic risk was found in a retrospective multicenter study, which analyzed the type and prevalence of birth defects among 911 infants whose mothers received letrozole to induce ovulation (i.e., under exposure conditions predating pregnancy).

Although it may not be possible to extrapolate directly from animal studies to human pathology, animal study demonstrated that gestational exposure to doses of letrozole that are equal to or lower than the daily recommended human dose has toxic effects on prenatal development (Tiboni et al., 2008).

\section{CONCLUSION}

In conclusion, the reported case here mandates that babies delivered as a consequence of ovulation induction with aromatase inhibitors should be examined antenatal and postnatally for possible congenital anomalies and to be reported to settle the argument weather theses medications are safe or not in term of ovulation induction.

\section{REFERENCES}

Al-Fadhli, R., C. Sylvestre, W. Buckett, S.L. Tan and T. Tulandi, 2006. A randomized trial of superovulation with two different doses of letrozole. Fertil Steril, 85: 161-164. PMID: 16412748

Biljan, M.M., R. Hemmings and N. Brassard, 2005. The Outcome of 150 Babies following the treatment with letrozole or letrozole and gonadotropins. Fertil Steril, 84: S95-S95. DOI: 10.1016/j.fertnstert.2005.07.230

Casper, R.F. and M.F.M. Mitwally, 2006. Aromatase inhibitors for ovulation induction. J. Clin. Endocrinol. Metab., 91: 760-771. DOI: $10.1210 /$ jc. $2005-1923$

Dickey, R.P., 2009. Strategies to reduce multiple pregnancies due to ovulation stimulation. Fertil Steril, 91: 1-17. DOI: 10.1016/j.fertnstert.2008.08.008

Haynes, B.P., M. Dowsett, W.R. Miller, J.M. Dixon and A.S. Bhatnagar, 2003. The pharmacology of letrozole. J. Steroid Biochem. Mol. Biol., 87: 3545. DOI: 10.1016/S0960-0760(03)00384-4

Holzer, H., R. Casper and T. Tulandi, 2006. A new era in ovulation induction. Fertil Steril, 85: 277-284. DOI: 10.1016/j.fertnstert.2005.05.078

Shepard, T.H. and R.J. Lemire, 2004. Catalog of Teratogenic Agents. 11th Edn., JHU Press, Baltimore, ISBN: 0801879531, pp: 510,

Tiboni, G.M., F. Marotta, C. Rossi and F. Giampietro, 2008. Effects of the aromatase inhibitor letrozole on in utero development in rats. Hum. Reprod., 23: 1719-1723. DOI: 10.1093/humrep/den100

Tulandi, T., J. Martin, R. Al-Fadhli, N. Kabli and R. Forman et al., 2006. Congenital malformations among 911 newborns conceived after infertility treatment with letrozole or clomiphene citrate. Fertil Steril, 85: 1761-1765. DOI: 10.1016/j.fertnstert.2006.03.014

Ziegler, D.D., C. Mattenberger, C. Luyet, I. Romoscanu and N.F. Irion et al., 2005. Clinical use of aromatase inhibitors (AI) in premenopausal women. J. Steroid Biochem. Mol. Biol., 95: 121127. DOI: $10.1016 /$ j.jsbmb.2005.04.023 